\title{
SHEAR BEHAVIOR OF TRAPEZOIDAL BEAMS
}

\author{
Ayman Hussein Khalil ${ }^{1}$, Mohamed Nabil ${ }^{1}$ and Mohamed Moukhtar Mohamed ${ }^{2}$ \\ ${ }^{1}$ Ain Shams University, Cairo, Egypt \\ ${ }^{2}$ Structural Engineer , Cairo, Egypt
}

\begin{abstract}
Extensive research has been carried out on the behavior and shear strength of reinforced concrete beams. The available literature is voluminous and the state of the art review is given elsewhere. Numerous tests on beams have been conducted and reported in the literature. Many theories for predicting the shear strength have been advanced.

The shear strength is based on an average shear stress on full effective cross section $\quad(b * d)$, where $b=$ section width and $d=$ section depth.

For calculating shear resistance for Trapezoidal beams with variable width there is many methods and provisions in different codes to calculate the effective width of the section as shown below:

-E C: minimum Web width.

-ACI 318: average web width.

-AASHTO: the minimum of average width and 1.2 min width.

-LRFD: Minimum web width.

-BS 8110: average web width.

Results obtained by experimental work indicated that the shear behavior of the trapezoidal beams depend on the average width of the section.
\end{abstract}

KEY WORDS: Shear behavior, trapezoidal beams and variable width.

\section{INTRODUCTION}

The shear resistance of reinforced concrete beams has been a well-known research subject over the last several decades. Shear capacity of reinforced concrete beams depend on shear stress on full effective cross section and stirrups volume. For calculating shear resistance for Trapezoidal beams with variable width there is many methods and provisions in different codes to calculate the effective width of the section.

Since most of codes and especially Egyptian code take the minimum web width as the effective width and due to lack of study for the effective width in the trapezoidal beams therefore more studies and research should be done in this field.

The main purpose of the present research study is to investigate the effect of cross section area on the capacity of reinforced concrete beams and Compare the recommendation in different codes. 


\section{LITERATURE REVIEW}

In spite of the numerous efforts directed at the shear capacity of concrete, there is still great discord concerning the mechanisms that govern shear in concrete. The shear mechanism is not well defined and is considered to be one of the most complex mechanisms for rationalization into a simple model. A lot of models are introduced by different theories using several assumptions related to the material properties and the internal mechanism. Therefore, a review of the actions and the mechanism of shear transfer in reinforced concrete beam are provided to highlight the problem of shear design.

Various methods of predicting the shear capacity of reinforced concrete elements have been proposed in research over the past one hundred years. Most of the methods are based on the $45^{\circ}$ truss model proposed by Morsch in the late 19th century. This model has been used in ACI codes over the years with success, but has been shown by many authors to give variable results. The variability in the results obtained experimentally show that it can be too conservative.

\subsection{Shear behavior of reinforced concrete beams}

A flexural member supports loads by internal moment and shear forces. Classical beam theory, in which plane sections are assumed to remain plane, provides an accurate, simple, and effective model for designing a member to resist bending in combination with axial forces. The simplicity and rationality of beam theory can be kept even after cracking for several reasons. The first reason is that flexural crack form perpendicular to the axis of bending so that the traditional "plane sections remain plane" assumption is valid. The second reason is the weakness of concrete in tension, so that tensile stresses can be effectively neglected at a crack. The third reason is that flexural failure occurs at the maximum moment location so that consideration of conditions at the maximum moment section is sufficient for flexural design.

Shear failure is initiated by inclined cracks caused not only by shear force but also by shear force in combination with moment and axial loads. The shear failure load depends on numerous factors such as the dimension, geometry, loading and structural properties of members. Because shear cracks are inclined and the shear failure load depends on a large number of factors, shear design-unlike flexural design- must consider the response of a finite length of the member, rather than the response of a single section. Due to the complications of the shear behavior and the difficulties of shear design, the shear behavior and shear strength of members have been major areas of research in reinforced and pre-stressed concrete structures for decades.

\subsubsection{Mechanisms of shear transfer in reinforced concrete beams}

Shear transfer actions and mechanisms in concrete beams are complex and difficult to clearly identify. Complex stress redistributions occur after cracking, and those redistribution have been shown to be influenced by many factors. Different researches impose different levels of relative importance to the basic mechanisms of shear transfer.

Figures (2.1.a) \& (2.1.b) shows the basic mechanisms of shear transfer that are now generally accepted in the research community for cracked beam without and with stirrups.

\subsubsection{Internal forces in beams without stirrups}

The forces transferring shear forces across an inclined crack in a beam without stirrups are illustrated in fig. (2.1.a). In this figure, Qa is the shear transferred across the crack by interlock of the aggregate particles on the two faces of the crack. Qax and Qay are the horizontal and vertical components of this forces, respectively. The shear force is resisted by: Qcz, the shear in the compression zone.

Qay, the vertical component of the shear transferred across the crack by the interlock of the aggregate particles on the two faces of the crack.

Qd, the dowels action of the longitudinal reinforcement. 


\subsubsection{Internal forces in beams with stirrups}

The purpose of web reinforcement is to prevent sudden shear failure and ensure that the full flexural capacity can be developed. Web reinforcement may either be consisting of vertical stirrups, inclined stirrups or bent bars as shown in fig. (2.1.b).

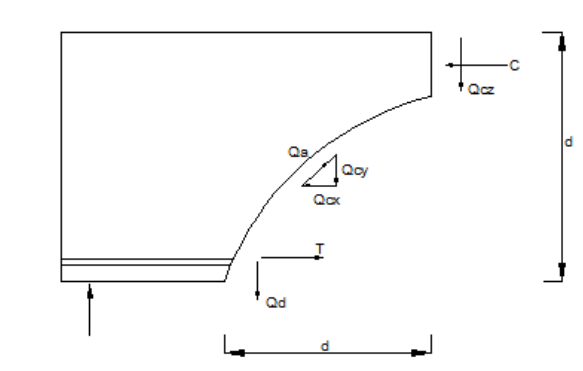

Fig. 2.1.a Internal Forces in a cracked beam without stirrups

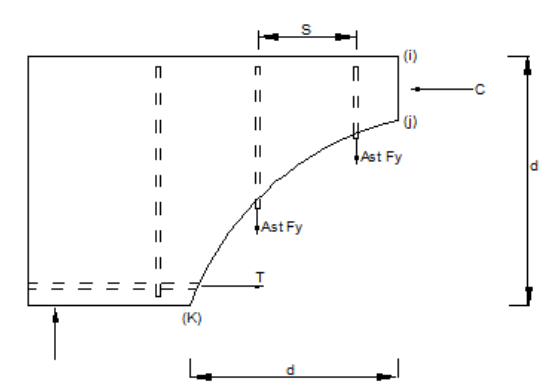

Fig. 2.1.b Internal Forces in a cracked beam with stirups

Measurements have shown that web reinforcement is almost free from stress prior to the formation of diagonal cracks. After diagonal cracking, web reinforcement affects the shear resistance of the beam in three separate ways:

Part of the shear force is resisted by the web reinforcement traversing the crack.

The presence of web reinforcement restricts the growth of diagonal cracks and reduces their penetration into the compression zone; and hence increases the part of the shear force resisted by the compression zone.

The presence of stirrups enhances the dowel action.

The shear transferred by tension in the stirrups is defined as Qs. Assuming that $\mathrm{n}$ is the number of stirrups crossing a crack, $\mathrm{s}$ is the spacing between stirrups, the crack angle is 45 degrees, and that the stirrups yield, then

$n=d \backslash s$

Qs $=$ n Ast Fy = Ast Fy d $\backslash$ s

Where

Ast: area of stirrups

\subsubsection{The transmission of shear force in concrete is mainly in the form of:} 2.1.1.3.1 Shear stress of concrete in compression zone, Qcz

The un-cracked compression zone contributes to shear resistance in a cracked concrete member (i.e. beam or slab). The magnitude of that shear resistance is limited by the depth of the compression zone. Consequently, in a relatively slender beam without axial compression, the shear contribution by the un-cracked compression zone becomes relatively small due to the small depth of the compression zone.

\subsection{Aggregate interlock diagonal crack plane, $Q$ a}

Local roughness in the crack plane provides resistance against sip and thus there is shear transfer across shear cracks. The contribution of interface shear transfer to shear strength is a function of the crack width and aggregate size. Thus, the magnitude decreases as the crack width increases and as the aggregate size decreases. Consequently, this component is also called "aggregate interlock".

However, it is now considered more appropriate to use the terminology "interface shear transfer" or "friction" since this action still exist even if crack propagation occurs through the aggregate as it does in high strength and light-weight concrete where the matrix is of a similar strength to the aggregates. The four basic parameters involved are the crack interface shear stress, normal stress, crack width, and crack slip. Walraven (1981) made numerous tests and developed a model that considered the probability that aggregate particles, idealized as sphere, would project from the crack interface figure (2.2). As slips develop, the matrix phase deforms plastically, coming into contact with projecting aggregates. The stresses in the 
contact zones are comprised of a constant pressure, $\sigma \mathrm{p}$, and a constant shear, $\mu \sigma \mathrm{p}$. the geometry of the crack surface is described statistically in terms of the aggregate content of the mix and the probabilities of particles projecting out at different degrees. In high strength concrete, the relatively smooth crack plane can reduce interface shear transfer compared to the rough crack plane of normal strength concrete.
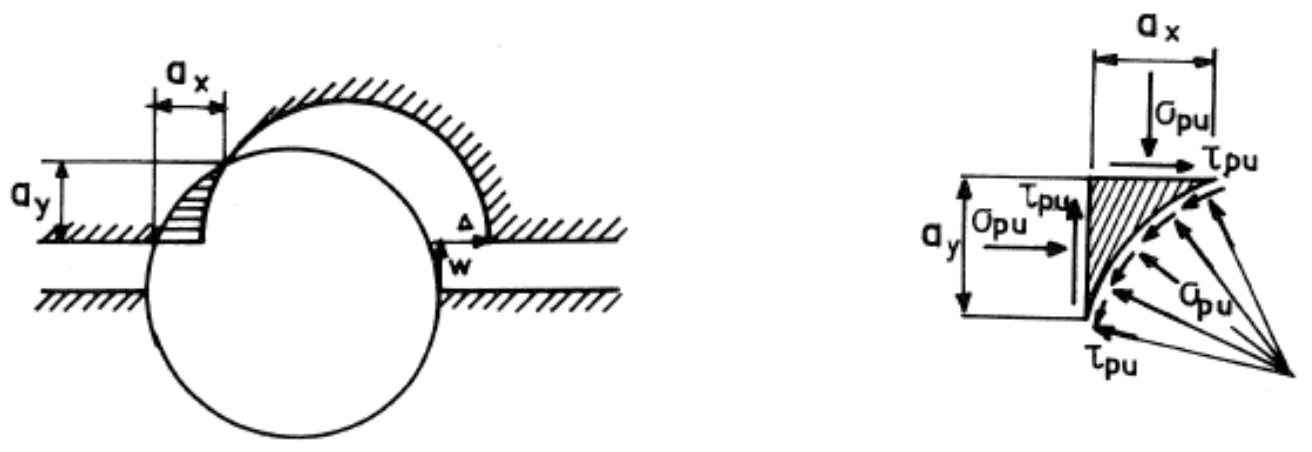

Figure (2.2) Walraven's Model of Crack Friction

\subsection{Dowel action of longitudinal reinforcement, $Q d$}

When a crack forms across longitudinal bars, the dowelling action of the longitudinal bars provides a resisting shear force. The contribution of dowel action to shear resistance is a function of the amount of concrete cover beneath the longitudinal bars and the degree to which vertical displacements of those bars at the inclined crack are restrained by transverse reinforcement. Typically, little dowel action can be provided by reinforcement that is near the tension face of a member without transverse reinforcement because that action is then limited by the tensile strength of the concrete. Nevertheless, it may be significant in beams with large amounts of longitudinal reinforcement, particularly when the longitudinal reinforcement is distributed in more than one layer.

\subsection{Shear reinforcement, Ast Fy}

In members with shear reinforcement, large portion of the shear is carried by the shear reinforcement after diagonal cracking occurs. The contribution of shear reinforcement to shear resistance is typically modeled either with a $45^{\circ}$ truss plus a concrete term, or a variable angle truss without a concrete term. Shear reinforcement also provides a certain level of restraint against the growth of inclined cracks and thus helps to insure a more ductile behavior. Finally, shear reinforcement provides dowelling resistance to shear displacement along the inclined crack. For these reasons, the presence of shear reinforcement changes the relative contribution of the different shear resisting mechanisms. The minimum amount of shear reinforcement required to affect such changes becomes important and that minimum amount is taken as a function of the concrete strength in most major design codes.

\subsection{Arch action}

The relative important of the arch action is direct related to the shear span to depth ratio, $(\mathrm{a} / \mathrm{d})$ (i.e. the distance from the support to the load over the effective depth). This is because as members become deeper, a large portion of the shear is transmitted directly to the support by an inclined strut. Beams without stirrups, with an (a/d) ratio of less than 2.5 develop inclined cracks and after a redistribution of internal forces, are able to carry an additional load due in part to arch action.

\section{Experimental Work}

\subsection{Experimental Program}

The experimental program will evaluate the shear resistance of trapezoidal beams with variable width as well as to validate and improve the current analytical and design approaches for shear analysis of normal reinforced concrete beams.

The experimental work of the present study consisted of testing eight direct models of RC beams tested to failure at the Reinforced Concrete Laboratory of the Structural Department of the Faculty of Engineering at Ain Shams University to investigate the modes of failure, the 
ultimate load carrying capacity and the shear behavior of the tested beams. The deformation, crack width, stirrup strain and longitudinal steel strain were also examined. The eight beam specimens were tested under two symmetric concentrated loads at distance $800 \mathrm{~mm}$ from each support, using special rigid steel frame providing the required eccentricity.

\subsection{DETAILS OF TESTED SPCIMENS:}

Figure (3.1) shows details of tested specimens with $2300 \mathrm{~mm}$ long and clear spans of 2000 $\mathrm{mm}$ and that the cross section dimensions were (175 Avg.) x $300 \mathrm{~mm}$. Figures (3.2-a) \& (3.2b) show that all the tested specimens had the same longitudinal reinforcement, the bottom reinforcement of all specimens was $4 \Phi 18$ and the stirrups were $8 \Phi 6$ for B5, B6, B7, B8 and there is no stirrups for B1, B2, B3, B4. The description of the tested specimens is shown in table (3.1).

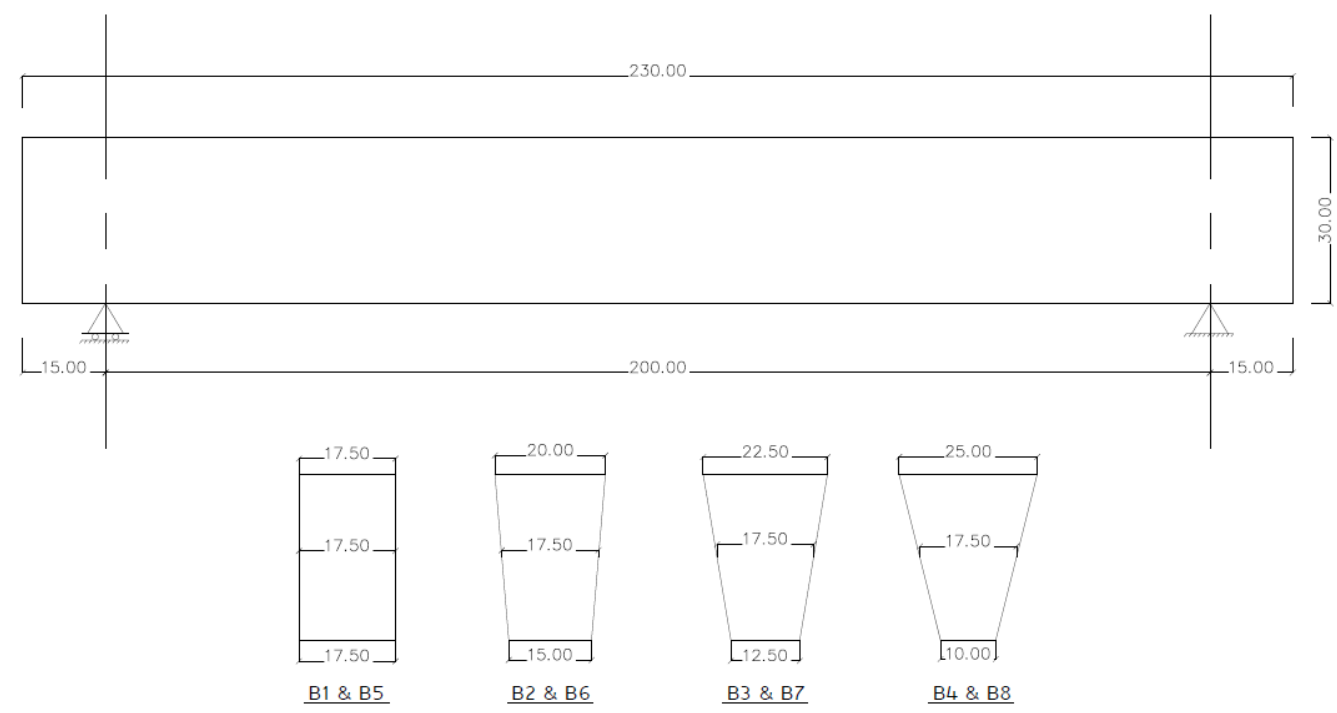

Figure (3.1): Details of tested specimens

Table (3.1): Description of the tested specimens

\begin{tabular}{|c|c|c|c|c|c|c|c|c|c|}
\hline \multicolumn{2}{|c|}{ Specimen } & B1 & B2 & B3 & B4 & B5 & B6 & B7 & B8 \\
\hline $\begin{array}{c}\text { Longitudinal } \\
\text { Steel Bars }\end{array}$ & Top & $2 \varnothing 12$ & $2 \varnothing 12$ & $2 \varnothing 12$ & $2 \varnothing 12$ & $2 \varnothing 12$ & $2 \varnothing 12$ & $2 \varnothing 12$ & $2 \varnothing 12$ \\
\cline { 2 - 10 } & Bottom & $4 \varnothing 18$ & $4 \varnothing 18$ & $4 \varnothing 18$ & $4 \varnothing 18$ & $4 \varnothing 18$ & $4 \varnothing 18$ & $4 \varnothing 18$ & $4 \varnothing 18$ \\
\hline \multicolumn{2}{|c|}{ Stirrups } & ----- & ----- & ----- & ----- & $8 \emptyset 6 / \mathrm{m}^{\prime}$ & $8 \varnothing 6 / \mathrm{m}^{\prime}$ & $8 \varnothing 6 / \mathrm{m}^{\prime}$ & $8 \emptyset 6 / \mathrm{m}^{\prime}$ \\
\hline $\begin{array}{c}\text { Concrete Compressive } \\
\text { Strength Fcu (MPA) }\end{array}$ & 25 & 25 & 25 & 25 & 25 & 25 & 25 & 25 \\
\hline
\end{tabular}


SHEAR BEHAVIOR OF TRAPEZOIDAL BEAMS
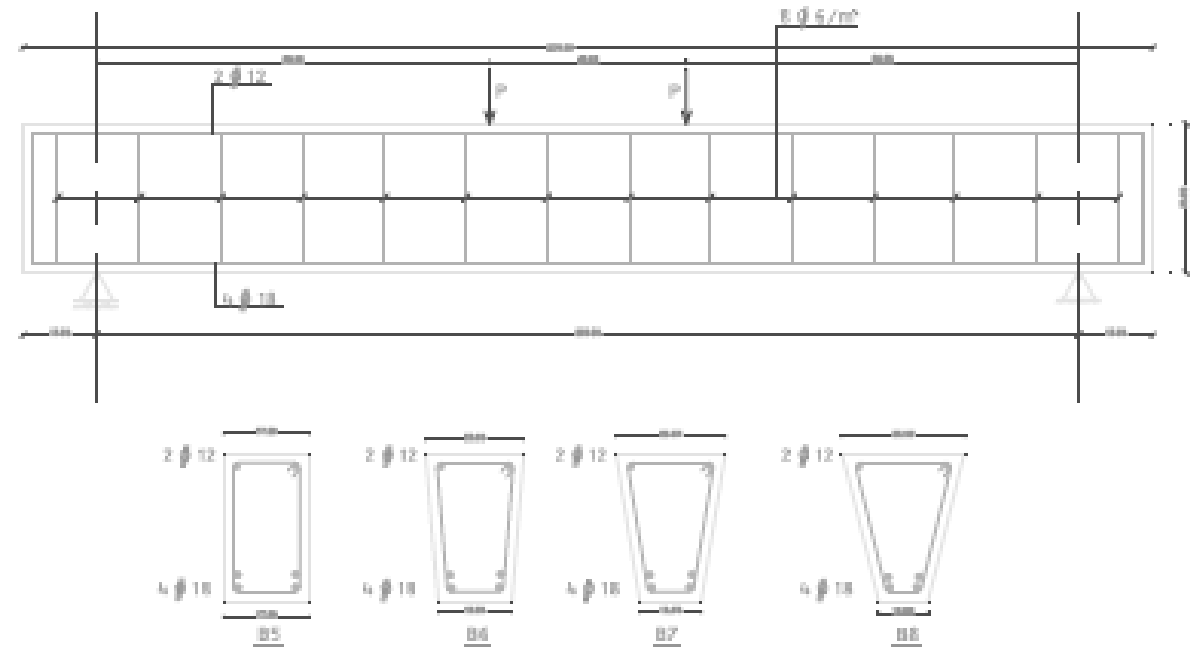

Figure (3.2-a): Details of reinforcement of specimens $(\mathrm{B5}, \mathrm{B6}, \mathrm{B} 7, \& \mathrm{B8})$

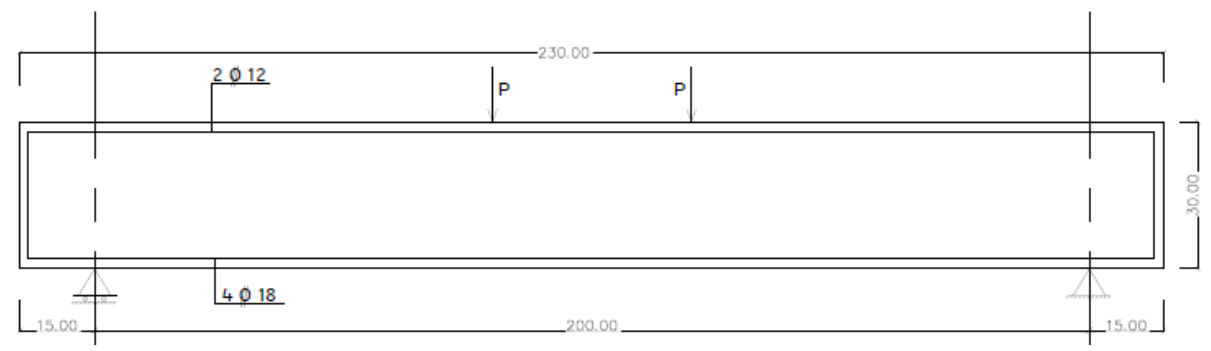

Figure (3.2-b): Details of reinforcement of specimens $(\mathrm{B} 1, \mathrm{~B} 2, \mathrm{B3}, \&$ B4)

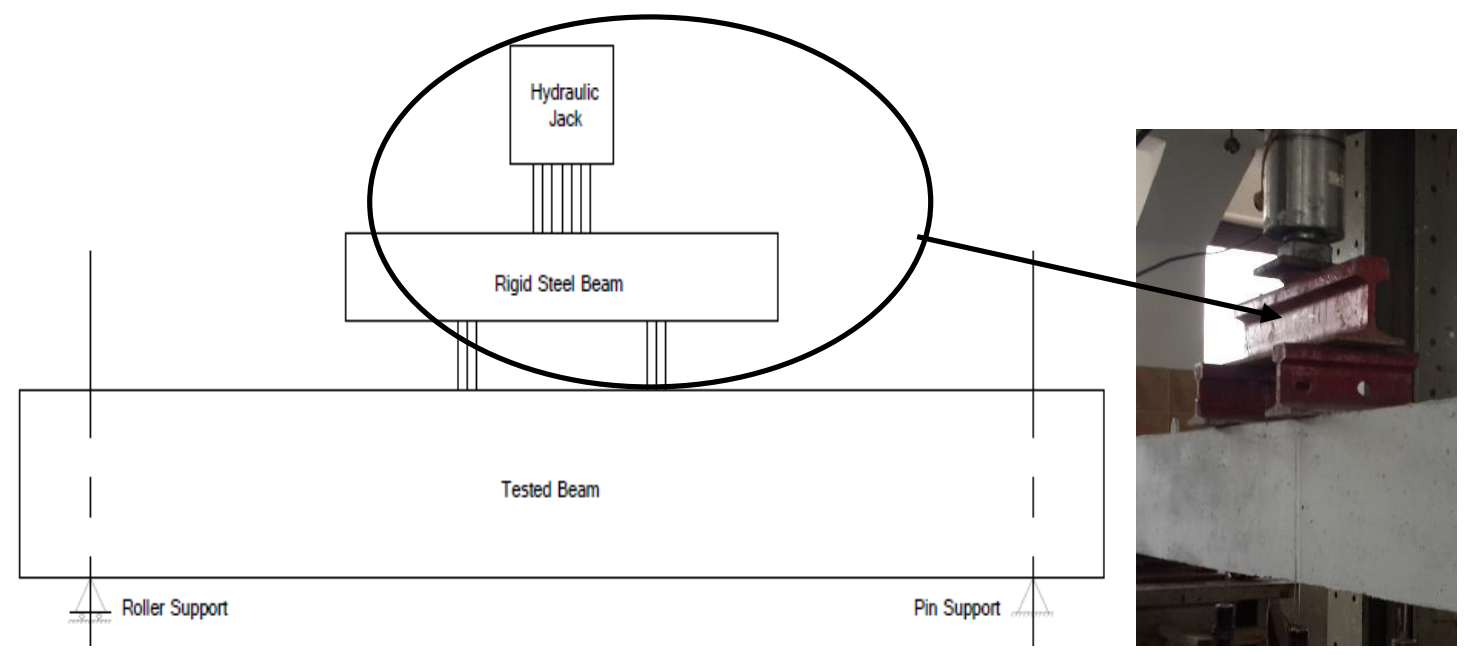

Figure (3.3): General setup of the tested specimens and the used hydraulic jack. 


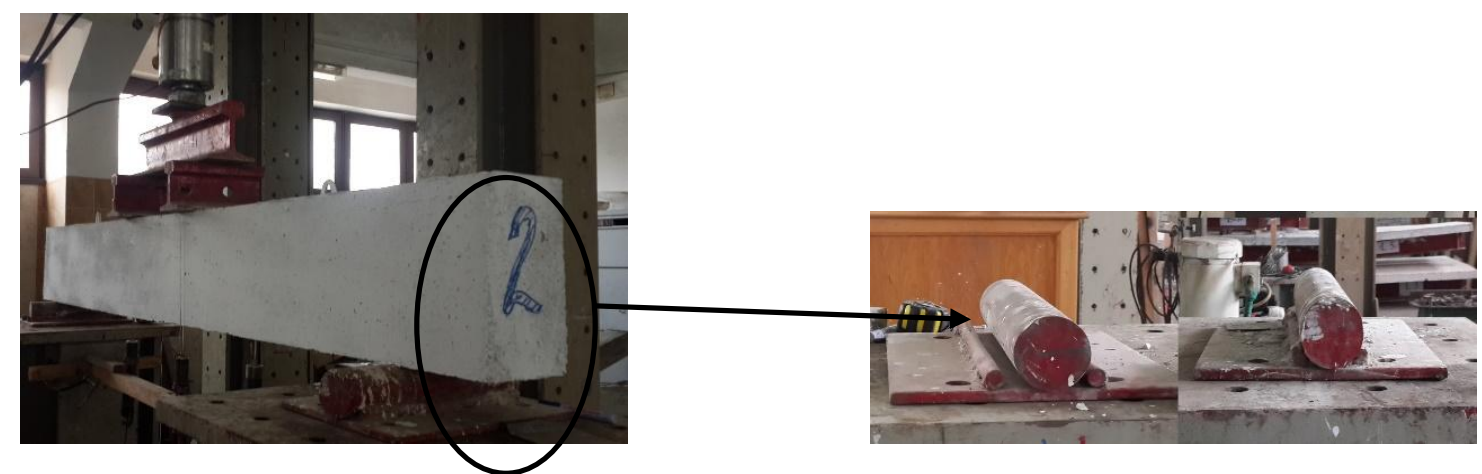

Photo (3.1): A beam specimen leveled and aligned in test setup and Details of the end supports

\subsection{Loading procedure}

The tested specimens were loaded statically from zero up to failure. One loading cycle was applied using 5 to 10 load increments till failure.

In this respect, $5 \mathrm{KN}$ load increments were used till cracking, in order to get accurate measurement of the cracking load. Afterwards, the load increments were increased to an average of $20 \mathrm{KN}$ till failure was reached. At the end of each load increment, the load was held constant for a period of about 2 minutes, to allow measurements and observations.

\section{Experimental Results and Discussion \\ 4.1 Behavior of the tested beams}

A summary of the test results for each tested beam specimen is shown in Table (4.1), includes the load of flexural cracking, load of shear cracking, load at shear failure, the mid-span deflection at failure and the mode of failure for the eight specimens were shear failure.

The flexural cracking load was determined based on the visual observation of cracks within flexural span between two concentrated loads in addition to load deflection curves, as the flexural cracking load is defined by the load at which the load-deflection relation begins to be nonlinear. Shear cracking load is defined by the load at which inclined crack crosses mid depth of the beam in the shear span, shear cracking load can be determined by recognizing the crack pattern, or from concrete strain, or from strain in critical stirrup which increases suddenly at this instant.

It should be noted that each beam was symmetrically loaded with two concentrated loads and consequently, the shear force is one-half the total applied load.

Table (4.1): Summary of test results of beam specimens

\begin{tabular}{|l|l|l|l|l|}
\hline Specimen & $\begin{array}{l}\text { Load at Flexural } \\
\text { cracking }(\mathrm{KN})\end{array}$ & $\begin{array}{l}\text { Load at Shear } \\
\text { cracking }(\mathrm{KN})\end{array}$ & $\begin{array}{l}\text { Load at } \\
\text { Failure (KN) }\end{array}$ & $\begin{array}{l}\text { Mid-span } \\
\text { deflection at failure } \\
(\mathrm{mm})\end{array}$ \\
\hline B1 & 76 & 104 & 104 & 3.19 \\
\hline B2 & 60 & 112 & 112 & 3.09 \\
\hline B3 & 55 & 95 & 95 & 2.83 \\
\hline B4 & 61 & 109 & 109 & 3.4 \\
\hline B5 & 68 & 130 & 186 & 7.64 \\
\hline B6 & 70 & 140 & 200 & 8.26 \\
\hline B7 & 60 & 120 & 202 & 7.94 \\
\hline B8 & 74 & 135 & 191 & 7.46 \\
\hline
\end{tabular}

1-The relation between load and deflection is nearly linear until cracking occurs, then the slope of line change with the increase of load.

2-The first crack appeared near the mid span section. This is due to the combined action of shear and bending. 
3-For the specimens with shear stirrups (B5, B6, B7, \&B8), the first Shear crack appeared at the lower edge. As the load increased, the cracks propagated upwards diagonally with an inclination angle of 40 to 50 degree approximately towards the point loads and became wider. 4-For the specimens without shear stirrups (B1, B2, B3, \&B4), brittle shear failure occurred suddenly.

\subsubsection{Cracking, Crack Patterns and Failure Load}

From the observed behavior of the tested beams specimens, the eight models behaved in two manners with respect to the presence of shear stirrups or not and the following remarks could be concluded: For the Specimens with shear stirrups, crack formation was initiated in the flexural span between the two concentrated loads where the flexural stress is highest and shear stress is zero. The cracks were vertical perpendicular to the direction of the maximum principal tensile stress induced by pure bending. As load increased, additional flexural cracks opened within the shear span. Due to effect of combined shear and bending stress, the existing flexural cracks extended into flexure-shear cracks. With increasing the load, additional shear cracks were formed in the shear span between the applied load and the support.

For the Specimens without shear stirrups, crack formation was initiated in the flexural span between the two concentrated loads where the flexural stress is highest and shear stress is zero. The cracks were vertical perpendicular to the direction of the maximum principal tensile stress induced by pure bending. As load increased, additional flexural cracks opened within the shear span. Due to effect of combined shear and bending stress, brittle shear failure occurred. The shear cracking load given in table (4.1) was determined based on the following instrumentation data, in addition to the visual observation of cracks:

The strains in the stirrups measured by the means of steel strain gauges attached to the stirrups in the shear span. Table (4.1) shows that, shear cracking was initiated after flexural cracking for all beam specimens. In general, shear cracks are characterized by irregular distribution as compared to flexural cracks. Shear cracking irregularity is attributed to the minor cracks that link the major shear cracks, as shown in photographs (4.1) to (4.8).

Both shear and flexural cracks were marked at each load level during the test up to the load level just before failure.

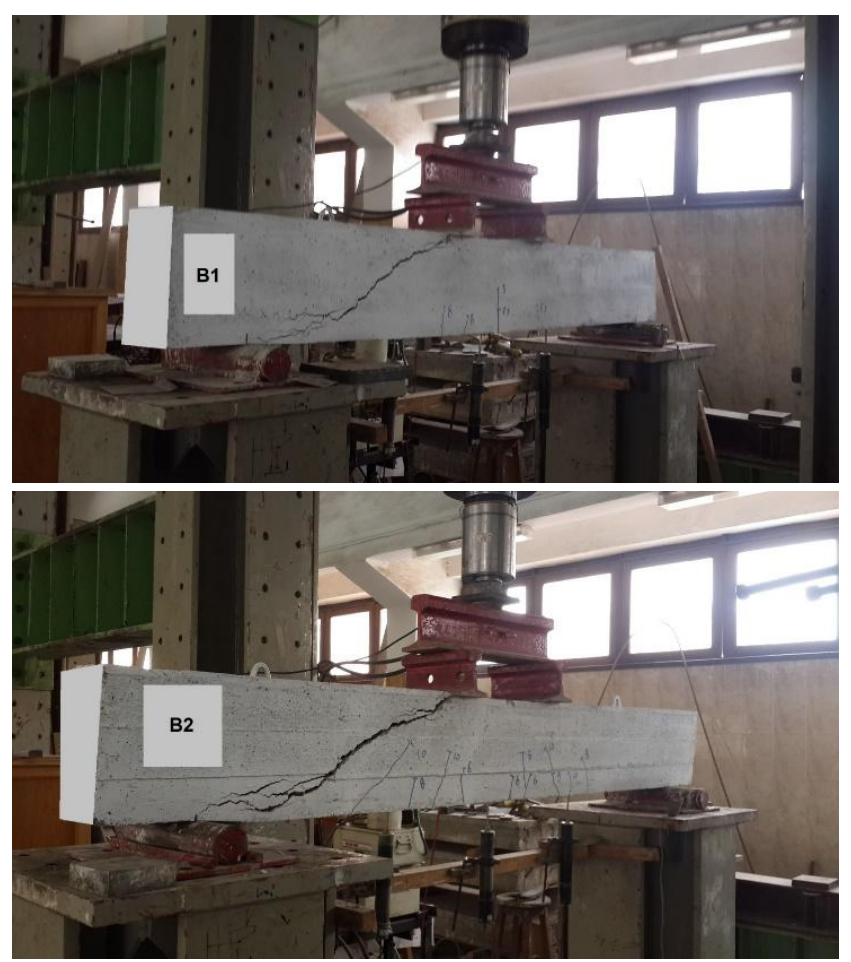

Photo (4.1): Crack Pattern of beam specimen (B1) Photo (4.2): Crack Pattern of beam specimen 
SHEAR BEHAVIOR OF TRAPEZOIDAL BEAMS
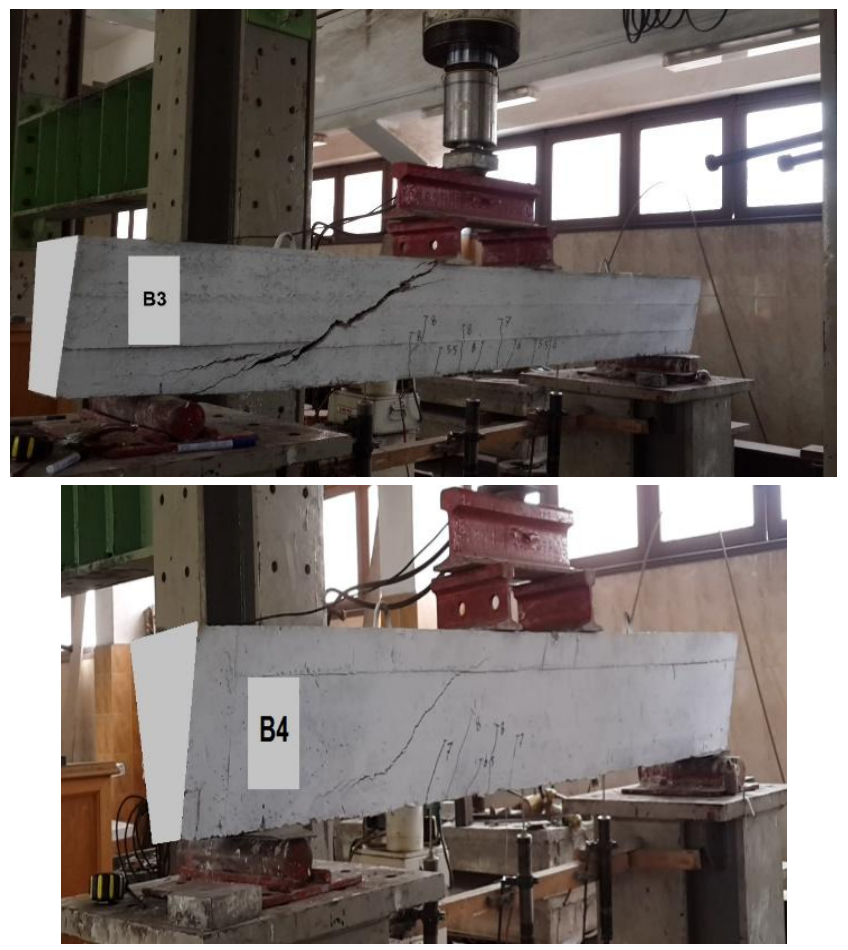

Photo (4.3): Crack Pattern of beam specimen (B3) Photo (4.4): Crack Pattern of beam specimen
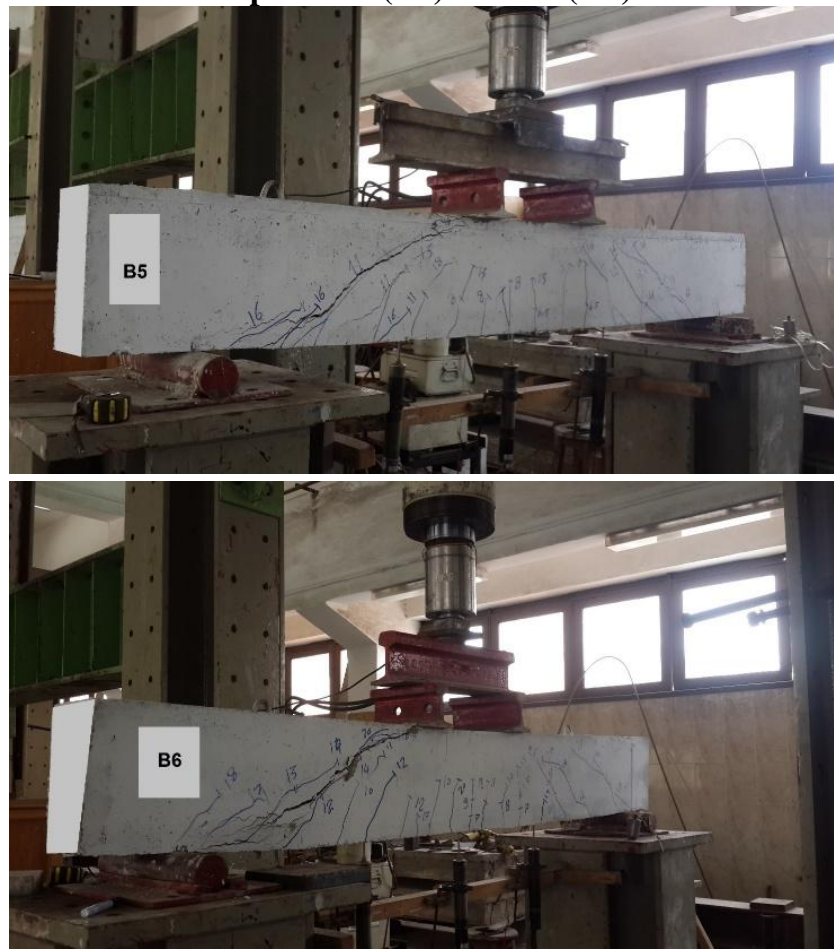

Photo (4.5): Crack Pattern of beam specimen (B5) Photo (4.6): Crack Pattern of beam specimen 
SHEAR BEHAVIOR OF TRAPEZOIDAL BEAMS

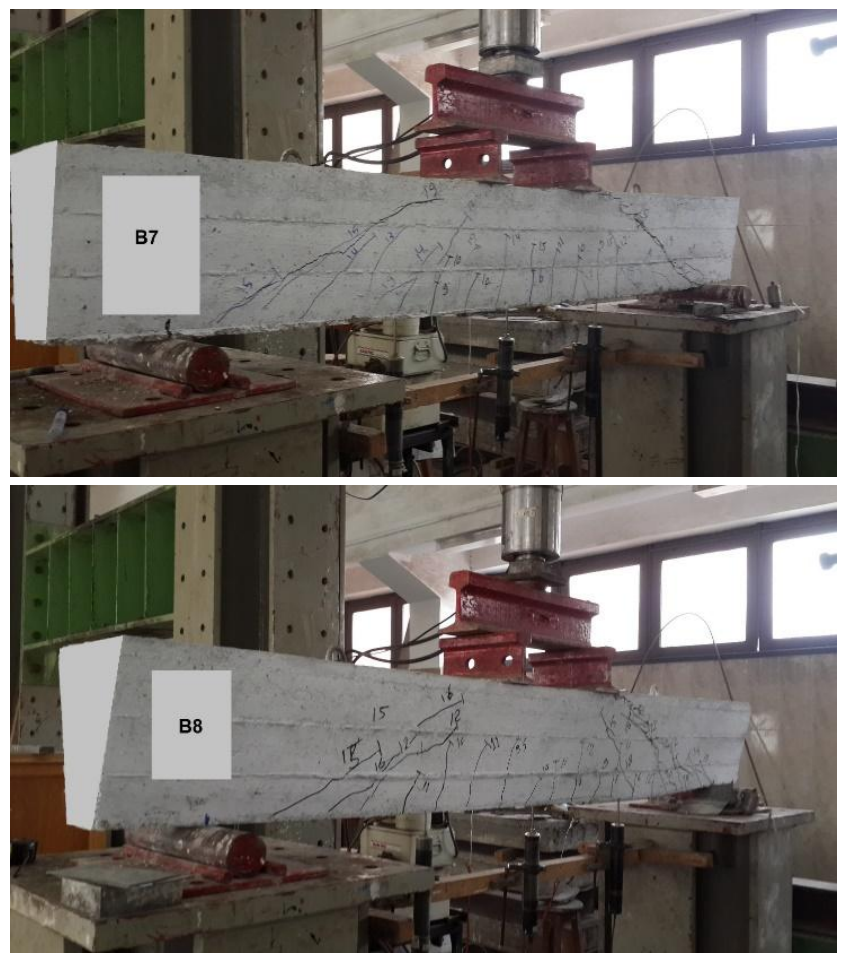

(B8)

Photo (4.7): Crack Pattern of beam specimen (B7) Photo (4.8): Crack Pattern of beam specimen

\subsubsection{Load-Deflection Response}

Vertical deformations of the tested beams were measured through all the span length of each model to predict the deflected shape of the tested beams.

Deflections of all beams were measured using linear variable displacement transducers (LVDTs) and recorded using a data acquisition system.

The applied load versus mid-span deflection relationships of the standard rectangular specimen without stirrups (B1) with the other three specimens (B2, B3 and B4) are represented in figures (4.1), (4.2) and (4.3) respectively, Figures (4.4), (4.5) and (4.6) shows the applied load versus mid-span relationships of the standard rectangular specimen with stirrups (B5) with the other three specimens (B6,B7 and B8) respectively, Figure (4.7) shows the applied load versus mid-span relationships of (B1 and B5), Figure (4.8) shows the applied load versus mid-span relationships of (B2 and B6), Figure (4.9) shows the applied load versus mid-span relationships of (B3 and B7), Figure (4.10) shows the applied load versus mid-span relationships of (B4 and B8). Also, Table (4.1) gives the mid-span deflection at failure for each beam.

The load-deflection curves for the beams were nearly linear at the early stages of loading (from zero loads up to the first cracking of the concrete). The reduction in the flexural stiffness due to cracking caused an increase in the deflection values. Approaching the failure load, the deflections continued to increase, while the applied load was maintained constant.

For the load-deflection relationship shown in figure (4.1) to (4.10), the maximum deflection for beam specimens was measured at the mid-span of the specimen.

\subsubsection{Load-deflection response of first group}

The variable between these specimens were the top and bottom width for the beam cross section with constant average width $(17.5 \mathrm{~cm})$. The four specimens have the same bottom reinforcement and without shear stirrups.

From figures (4.1), (4.2) and (4.3) the following remarks could be concluded. 
1-The first part of the load-deflection plot up to flexural cracking was similar for all beams representing the behavior of the un-cracked beam utilizing the gross moment of inertia of the concrete cross section. In this part the load deflection relationship was linear.

2-The second part, post cracking up to failure, represents the cracked beam with reduced moment of inertia.

3-The standard beam "B1" has the highest gross moment of inertia which lead to the lowest deflection value compared with the other specimens (B2, B3 \& B4) till the first crack occurs and then the section behavior depend on the cracked moment of inertia.

4-The standard beam "B1" cracked moment of inertia is the lowest compared with the other specimens (B2, B3 \& B4) which lead to the highest deflection value after the first crack occurs till failure.

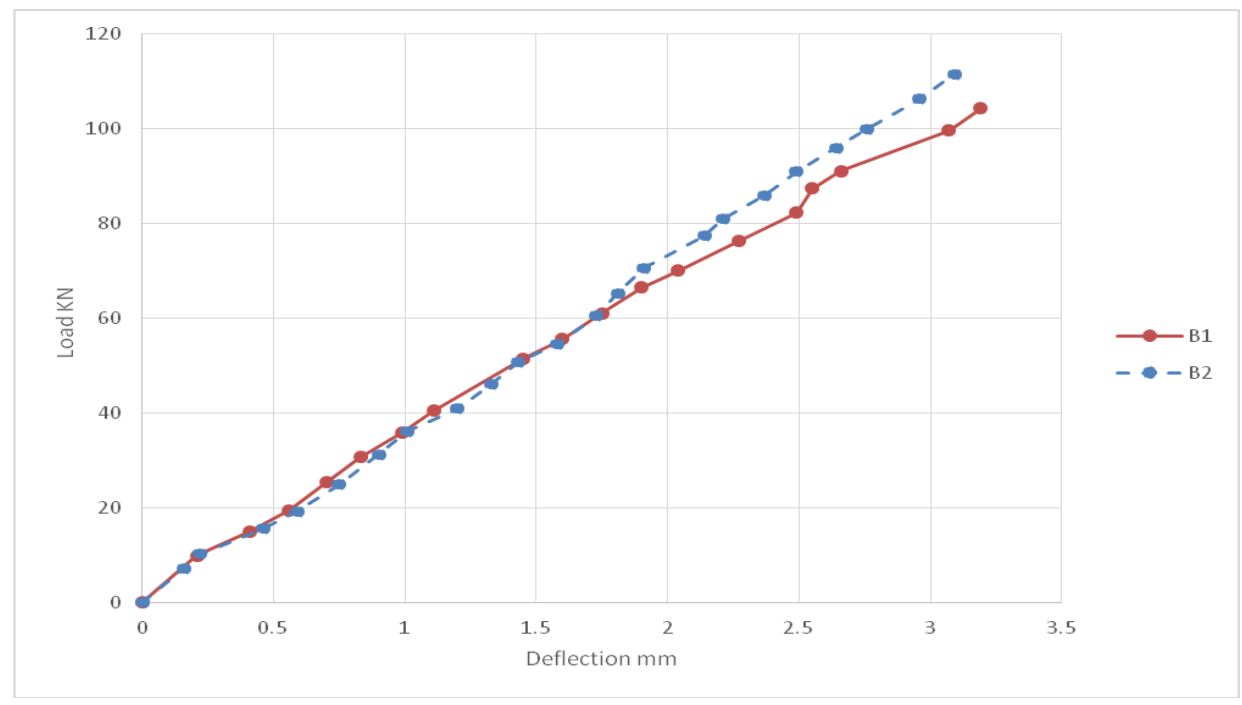

Figure (4.1): Mid-Span Load-deflection curves for specimens (B1 and B2)

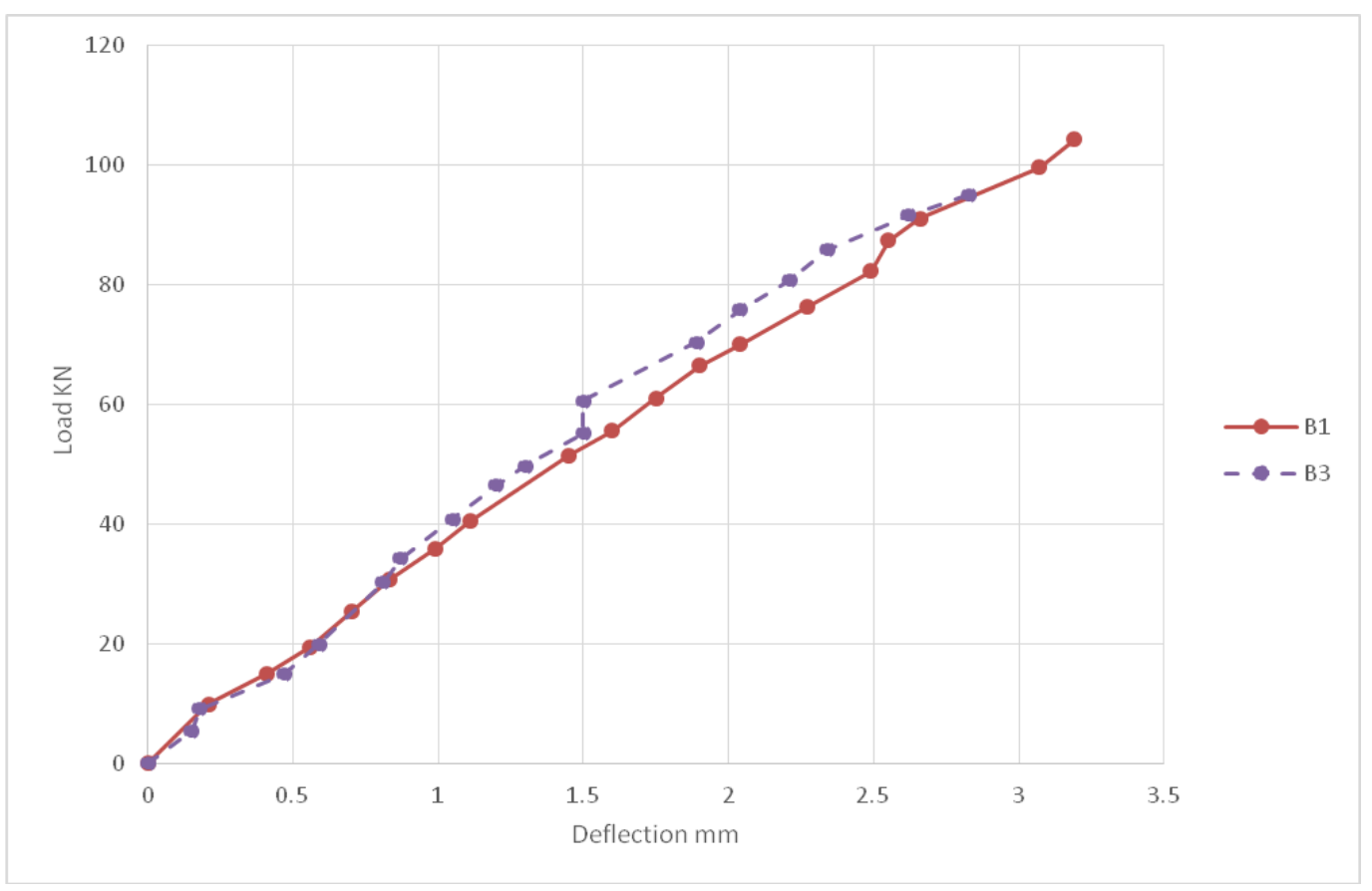

Figure (4.2): Mid-Span Load-deflection curves for specimens (B1 and B3) 


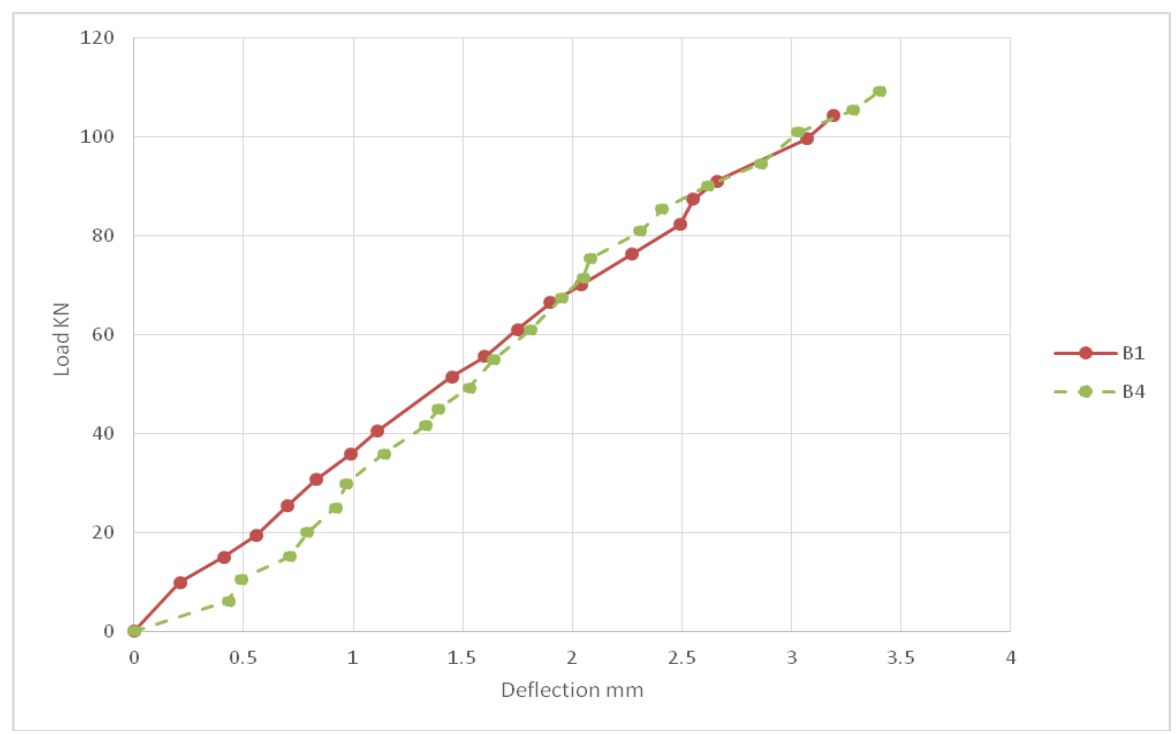

Fig. (4.3): Mid-Span Load-deflection curves for specimens (B1 and B4)

\subsubsection{Load-deflection response of second group}

The variable between these specimens were the top and bottom width for the beam cross section with constant average width $(17.5 \mathrm{~cm})$. The four specimens have the same bottom reinforcement and the same shear stirrups. From figures (4.4), (4.5) and (4.6) the following remarks could be concluded.

1-The first part of the load-deflection plot up to flexural cracking was similar for all beams representing the behavior of the un-cracked beam utilizing the gross moment of inertia of the concrete cross section. In this part the load deflection relationship was linear. 2-The second part, post cracking up to failure, represents the cracked beam with reduced moment of inertia. 3-The standard beam "B5" has the highest gross moment of inertia which lead to the lowest deflection value compared with the other specimens (B6, B7 \& B8) till the first crack occurs and then the section behavior depend on the cracked moment of inertia.

4-The standard beam "B5" cracked moment of inertia is the lowest compared with the other specimens (B6, B7 \& B8) which lead to the highest deflection value after the first crack occurs till failure.

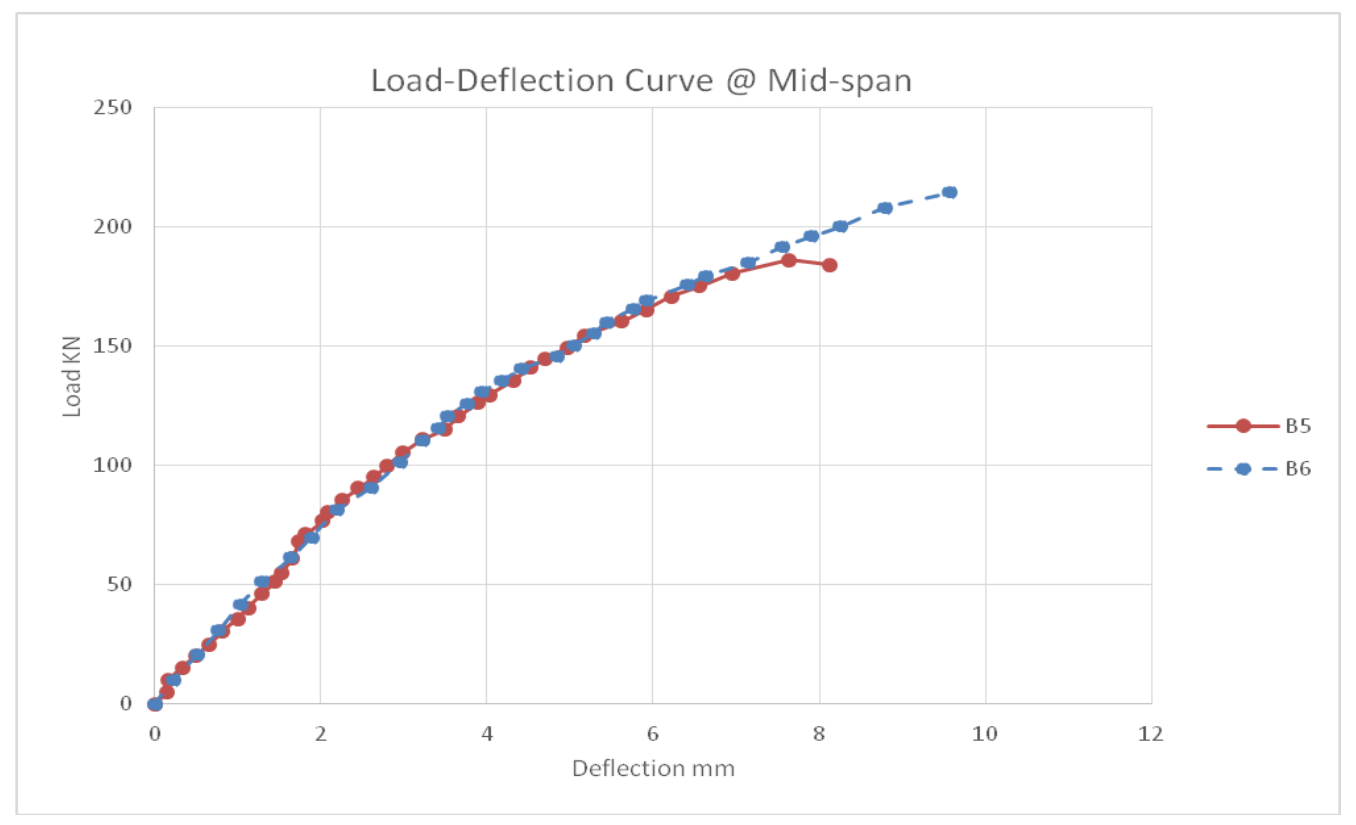

Figure (4.4): Mid-Span Load-deflection curves for specimens (B5 and B6) 


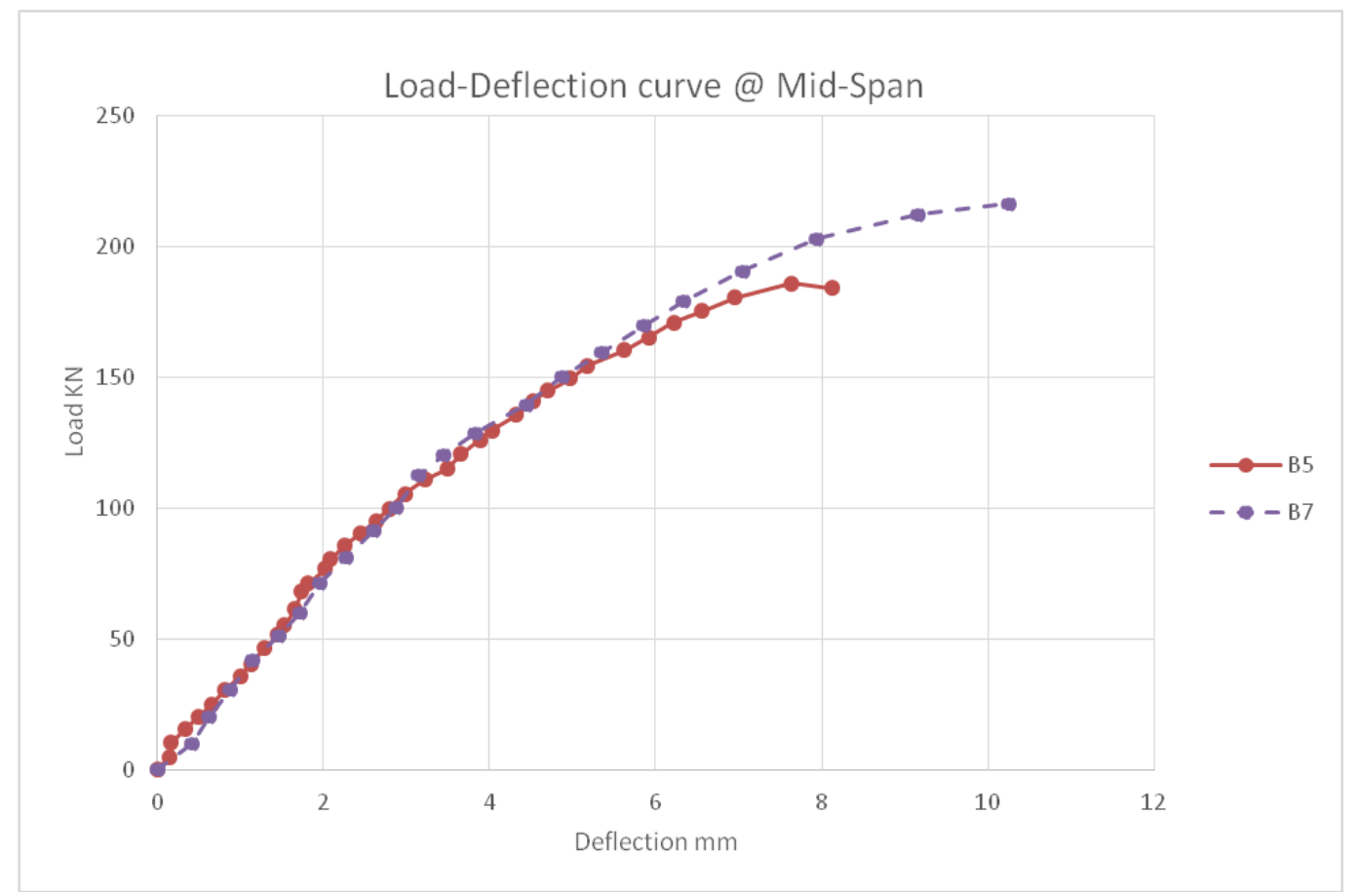

Figure (4.5): Mid-Span Load-deflection curves for specimens (B5 and B7)

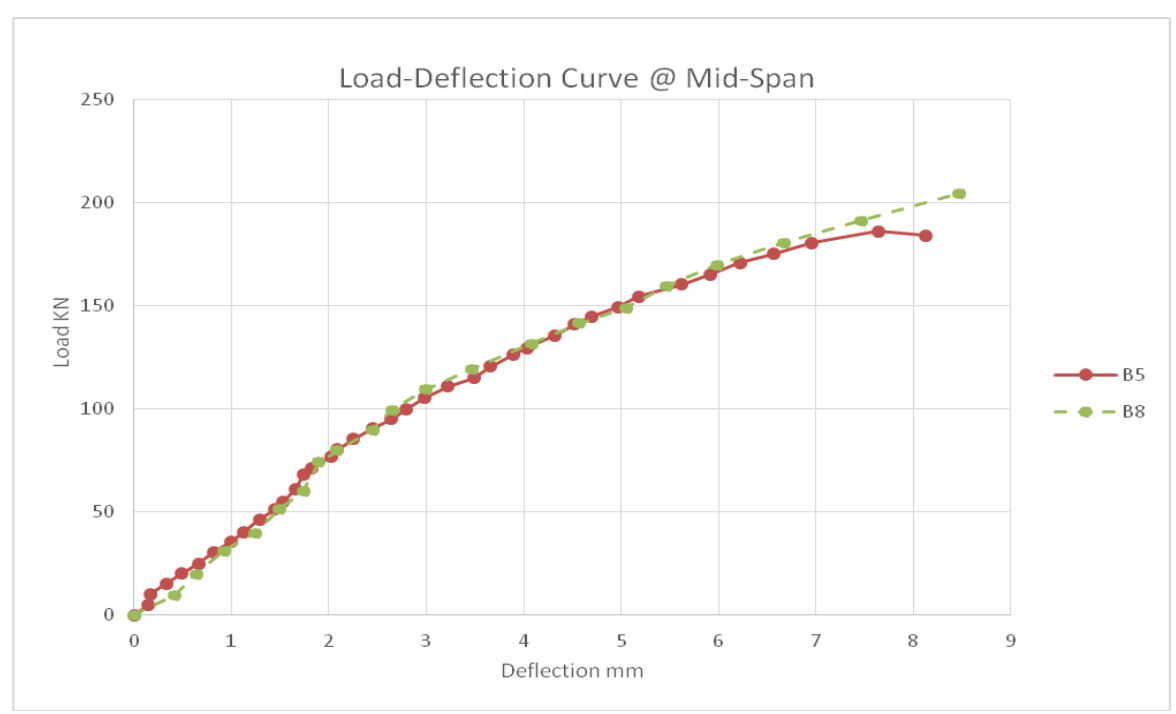

Figure (4.6): Mid-Span Load-deflection curves for specimens (B5 and B8)

\subsubsection{Load-deflection response of third group}

The variable between the two beams is that B1 without shear stirrups while B5 with shear stirrups. Both beams has the same cross section width and the same bending reinforcement. From figure (4.7) the following remarks could be concluded.

1-The first part of the load-deflection plot up to flexural cracking was similar for all beams representing the behavior of the un-cracked beam utilizing the gross moment of inertia of the concrete cross section. In this part the load deflection relationship was linear.

2-The second part, post cracking up to failure, represents the cracked beam with reduced moment of inertia.

3-The two beams have the same behavior till a brittle shear failure occurs for "B1" due to the absence of shear stirrups and "B5" continue till the stirrups reach to yielding stress and ductile shear failure occurs. 


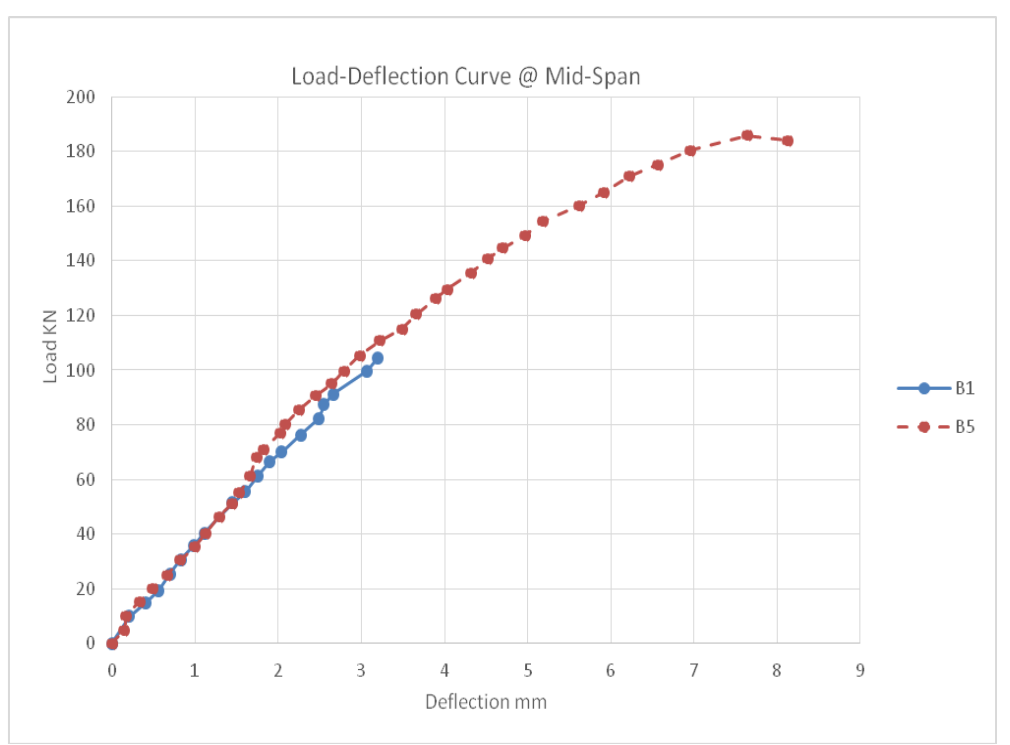

Figure (4.7): Mid-Span Load-deflection curves for specimens (B1 and B5)

\subsubsection{Load-deflection response of fourth group}

The variable between the two beams is that B2 without shear stirrups while B6 with shear stirrups. Both beams has the same cross section width and the same bending reinforcement.

From figure (4.8) the following remarks could be concluded.

1-The first part of the load-deflection plot up to flexural cracking was similar for all beams representing the behavior of the un-cracked beam utilizing the gross moment of inertia of the concrete cross section. In this part the load deflection relationship was linear.

2-The second part, post cracking up to failure, represents the cracked beam with reduced moment of inertia. 3-The two beams have the same behavior till a brittle shear failure occurs for "B2" due to the absence of shear stirrups and "B6" continue till the stirrups reach to yielding stress and ductile shear failure occurs.

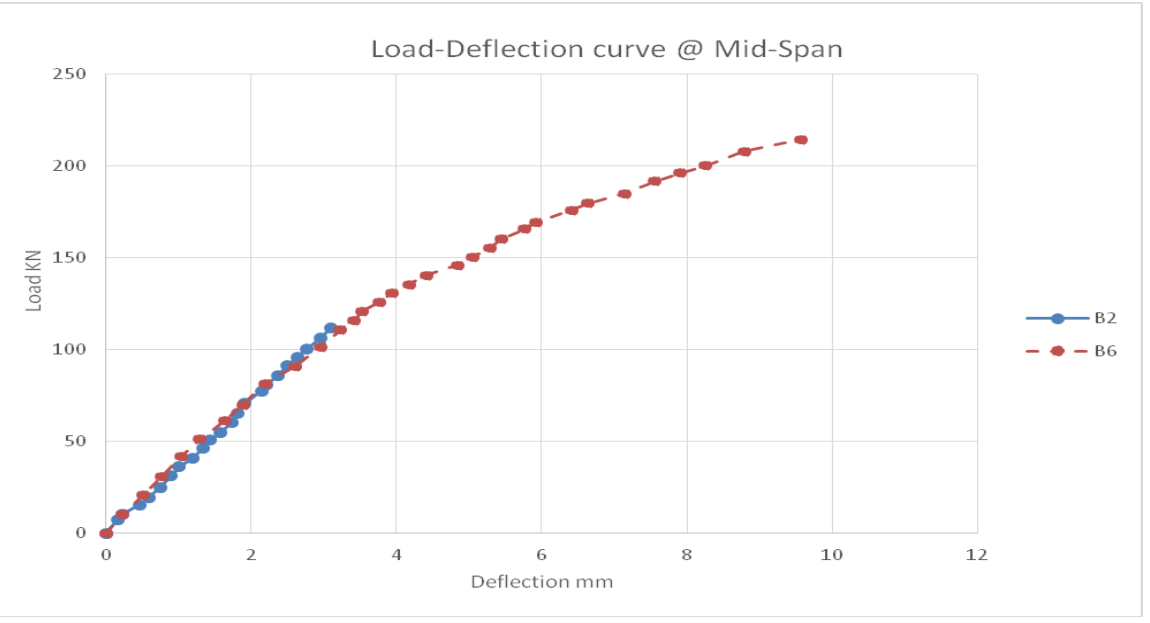

Figure (4.8): Mid-Span Load-deflection curves for specimens (B2 and B6)

\subsubsection{Load-deflection response of fifth group}

The variable between the two beams is that B3 without shear stirrups while B7 with shear stirrups. Both beams has the same cross section width and the same bending reinforcement. From figure (4.9) the following remarks could be concluded.

1-The first part of the load-deflection plot up to flexural cracking was similar for all beams representing the behavior of the un-cracked beam utilizing the gross moment of inertia of the concrete cross section. In this part the load deflection relationship was linear. 
2-The second part, post cracking up to failure, represents the cracked beam with reduced moment of inertia.

3-The two beams have the same behavior till a brittle shear failure occurs for "B3" due to the absence of shear stirrups and "B7" continue till the stirrups reach to yielding stress and ductile shear failure occurs.

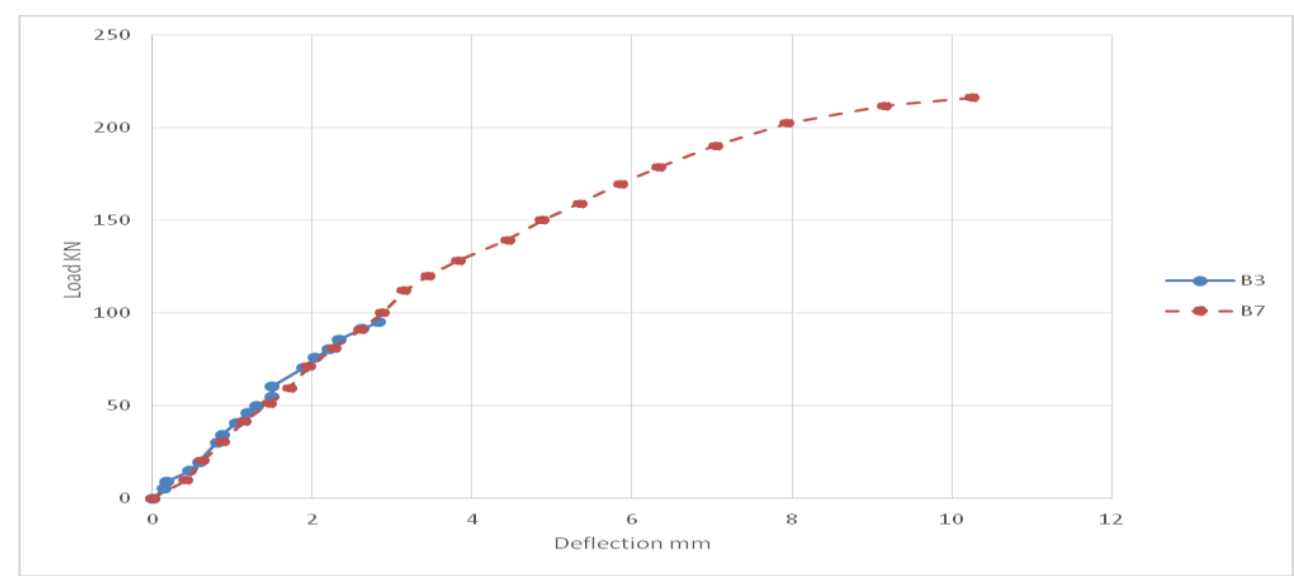

Fig. (4.9): Mid-Span Load-deflection curves for specimens (B3 and B7)

\subsubsection{Load-deflection response of sixth group}

The variable between the two beams is that B4 without shear stirrups while B8 with shear stirrups. Both beams has the same cross section width and the same bending reinforcement.

From figure (4.10) the following remarks could be concluded.

1-The first part of the load-deflection plot up to flexural cracking was similar for all beams representing the behavior of the un-cracked beam utilizing the gross moment of inertia of the concrete cross section. In this part the load deflection relationship was linear.

2-The second part, post cracking up to failure, represents the cracked beam with reduced moment of inertia.

3-The two beams have the same behavior till a brittle shear failure occurs for "B4" due to the absence of shear stirrups and "B8" continue till the stirrups reach to yielding stress and ductile shear failure occurs.

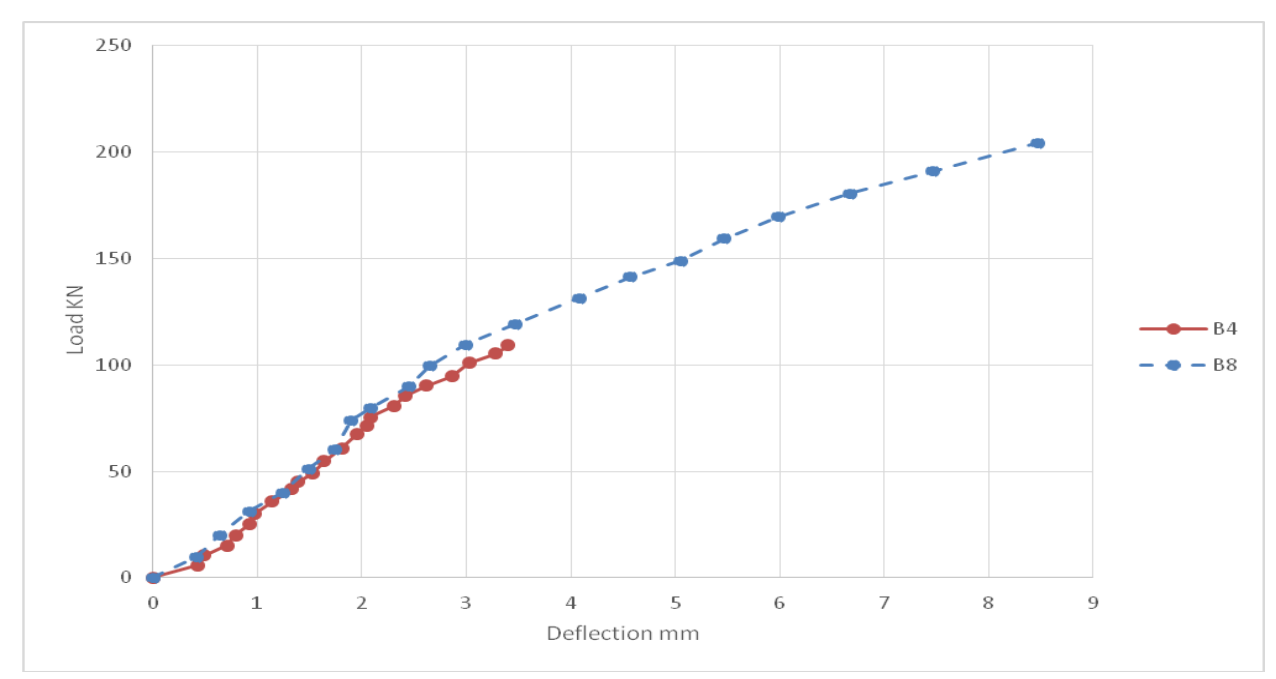

Figure (4.10): Mid-Span Load-deflection curves for specimens (B4 and B8) 


\subsubsection{Transverse Steel Strains}

The strains in the steel stirrups located within the tested shear span of each beam specimen, were measured up to failure using electric strain gauges as described in chapter (3).

Figures (4.11) to (4.13) show the average load-transverse steel strain for the tested beams which contain shear stirrups.

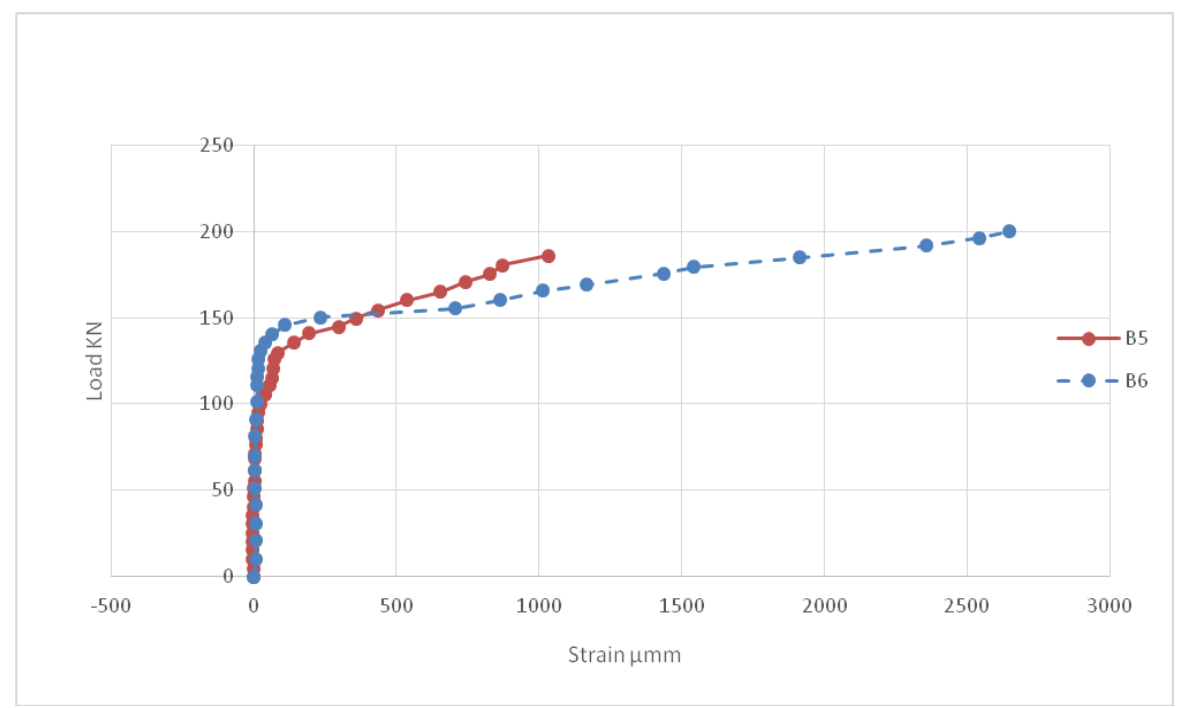

Figure (4.11): Transverse Steel Load-Strain Curve for (B5 and B6)

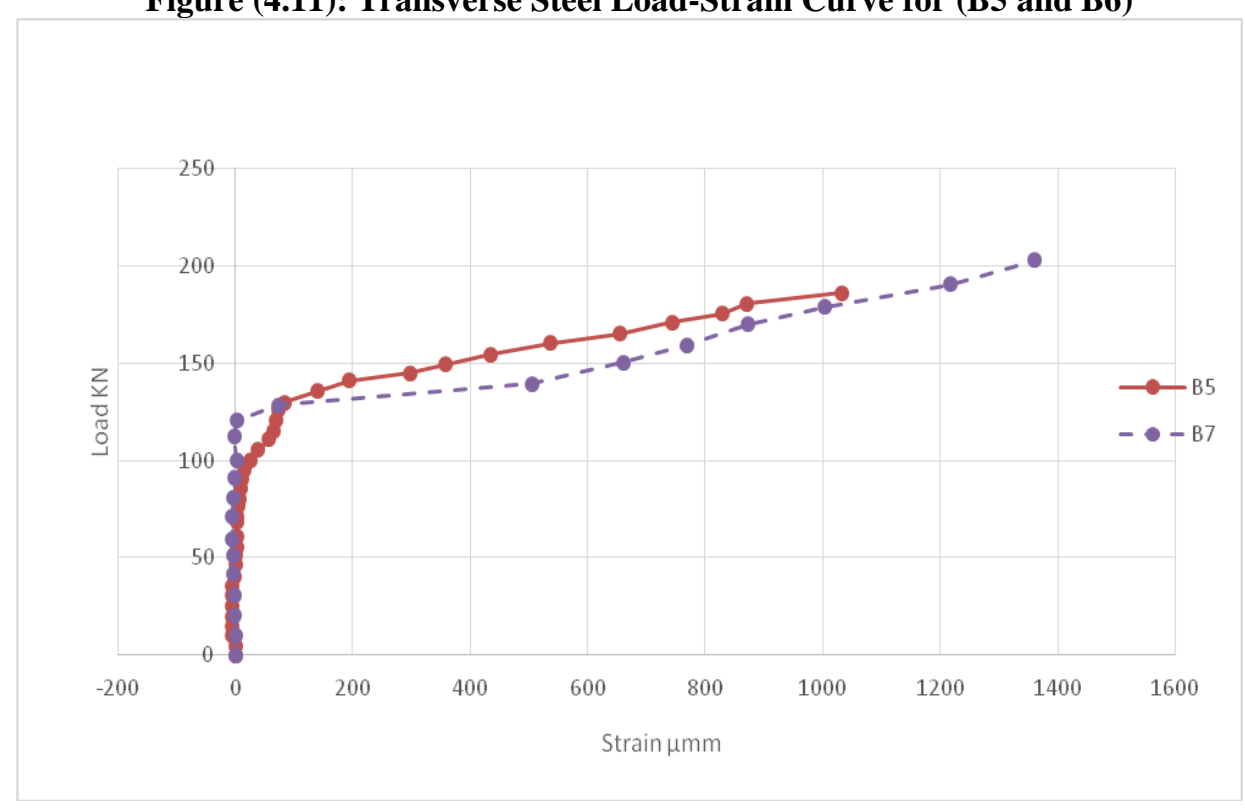

Figure (4.12): Transverse Steel Load-Strain Curve for (B5 and B7) 


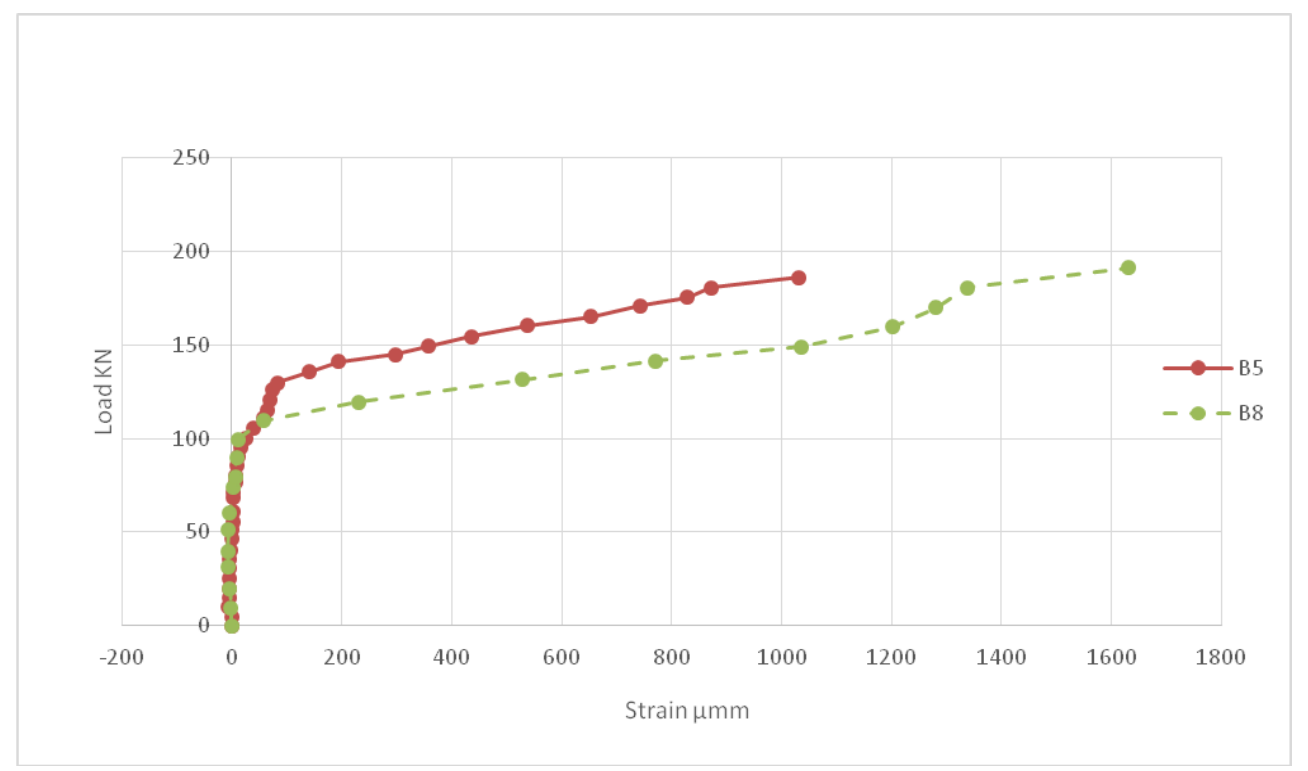

Figure (4.13): Transverse Steel Load-Strain Curve for (B5 and B8)

\subsection{Concluding Remarks}

The obtained experimental results of this chapter can be summarized as follows:

1-The first part of the load-deflection plot up to flexural cracking was similar for all beams representing the behavior of the un-cracked beam utilizing the gross moment of inertia of the concrete cross section. In this part the load deflection relationship was linear.

2-The second part, post cracking up to failure, represents the cracked beam with reduced moment of inertia.

3-The standard beams "B1 \& B5" have the highest gross moment of inertia which lead to the lowest deflection value compared with the other specimens (B2, B3, B4, B6, B7 \& B8) till the first crack occurs and then the section behavior depend on the cracked moment of inertia.

4-The standard beam "B1 \& B5" cracked moment of inertia is the lowest compared with the other specimens (B2, B3, B4, B6, B7 \& B8) which lead to the highest deflection value after the first crack occurs till failure.

5-The shear behavior of the beams depend on the average cross section area (the average width) in resisting shear force.

\section{REFERENCES}

[1] ACI Committee 318, "Building Code Requirements for Reinforced Concrete, "American Concrete Institute" 2008.

[2] (AASHTO), "American Association of State Highway and Transportation Officials" 2012

[3] BS 8110 , "British Standard for the design and construction of reinforced and prestressed concrete structures" 2004

[4] WALRAVEN, J. C., Mechanisms of shear transfer of cracks in concrete. A survey of literature. Stevin report 5-78-12, Delft University of Technology, Delft 1978.

[5] Kotsovos, Michael D, "Mechanisms of Shear Failure", "Magazine of concrete Research, V.35, No. 123, June 1983, pp. 99-106.

[6] Xie, Y; Ahmad, S.H; T.; Hino,S; and Chung, W, "Shear Ductility of reinforced concrete beams of normal and high strength concrete" ACI Structural Journal, V.91, No. 2 MarApr. 1994, pp. 140-149.

[7] Mphonde, A. G., and Frantz, G. C., "Shear Tests of High and Low Strength Concrete Beams Wthout Stirrups,"ACI Journal, Proceedings V.81, No. 4, July-Aug. 1984, PP. 350357.

[8] Braestrup, M. W., "Shear Strength Prediction-Plastic Method" Reinforced Conrete Deep Beams, F. K. Kong, ed., Blackie and son Ltd., Glasgow and London, and Van Nostrand Reinhold, N.Y., 1990 pp. $182-203$ 